\title{
OTOMATISASI PENYIRAMAN TANAMAN DENGAN METODE SAW MENGGUNAKAN ARDUINO BERBASIS WEB
}

\author{
(AUTOMATION OF WATERING PLANTS WITH SAW METHOD \\ USING WEB BASED ARDUINO)
}

\author{
Atmoko Nugroho, April Firman Daru, Agus Edy Cahyono \\ Fakultas Teknologi Informasi dan Komunikasi \\ Universitas Semarang \\ atmoko@usm.ac.id,firman@usm.ac.id,edyagusc@gmail.com
}

\begin{abstract}
Plants need water to grow and develop. Planting crops in the home environment can provide many benefits, including ensuring the availability of oxygen in the family, as a natural cooling of the house, and as a storage groundwater if the plants get watering and routine maintenance, the benefits derived from plants will be perceived by the family. Using clean water to water the plants every day is a wasteful behavior of water, because water is used for everyday purposes. In addition, the dense activities result in the existing plants at home tend to be lazy to water the plants. Well-groomed plants can provide adequate oxygen for the family.Many ways can be done to solve problems, using soil moisture sensors and temperature sensors to monitor the state of the plant at home, to determine the time of watering using decision support system with the method of SAW (Simple Additive Weighting) to determine the time of watering based on the results of the sensor readings on plants. The existence of this system can be saving water used for watering plants, and plants in the house fulfilled water needs, the benefits of plants can be felt.
\end{abstract}

Keywords: Plant, Arduino Nano, SAW (Simple Additive Weighting)

\section{PENDAhuluan}

Air adalah senyawa kimia yang merupakan hasil ikatan dari unsur hidrogen $(H 2)$ yang bersenyawa dengan unsur oksigen $(O)$ dalam hal ini membentuk senyawa $H 2 O$. Air merupakan senyawa kimia yang sangat penting bagi kehidupan makhluk hidup di bumi ini. Air sangat penting bagi tanaman, karena berfungsi sebagai, bahan baku dalam proses fotosintesis, pelarut unsur hara dalam tanah dan dalam tubuh tanaman serta sebagai media translokasi unsur hara dari dalam tanah ke akar untuk selanjutnya di kirim ke daun. Tanaman memiliki banyak manfaat di antaranya, sebagai tempat berteduh, penyejuk udara dan tanaman sebagai pembersih udara.

Untuk dapat tumbuh dan berkembang tanaman membutuhkan air, salah satu cara untuk memenuhi kebutuhan air pada tanaman adalah dengan melakukan penyiraman, seperti halnya menyiram tanaman di rumah, tanaman yang berada di taman - taman kota dan tanaman yang berada di sepanjang jalan serta tanaman budidaya. Dimana banyak air yang disiramkan melebihi batas kebutuhan air pada tanaman tersebut, perilaku ini merupakan perilaku boros air jika tanaman yang di lakukan penyiraman kelebihan air atau sifat manusia yang sibuk dengan hal lain mengakibatkan tanaman tidak mendapat penyiraman secara rutin maka tanaman kekurangan air.

Banyak cara yang dapat dilakukan untuk menyelesaikan permasalahan di atas, salah satunya dengan membuat sistem penyiraman otomatis dengan menggunakan sensor kelembapan tanah, humiditas dan suhu untuk memonitor keadaan tanaman di rumah yang di proses menggunakan mikrokontroler untuk memproses data dari sensor, untuk menentukan waktu penyiraman menggunakan sistem pendukung keputusan dengan metode SAW (Simple Additive Weighting) agar dapat ditentukan waktu penyiraman berdasarkan hasil dari pembacaan sensor yang di letakan pada tanaman. Pengguna dapat melakukan monitoring terhadap tanamannya mulai dari suhu, humiditas, dan kelembapan tanah, serta pengaturan jadwal penyiraman pada tanaman tersebut.

\section{LANDASAN TEORI}

Metode Simple Additive Weighting

Metode Sinple Additive Weight (SAW)

adalah salah satu metode yang dapat digunakan 
untuk menyelesaikan permasalahan Multi Attribut Decision Making (MADM). Konsep dasar Metode SAW adalah mencari penjumlahan terbobot dari rating kinerja dari setiap alternatif pada semua atribut. Metode SAW membutuhkan proses normalisasi matriks keputusan ke suatu skala yang dapat diperbandingkan dengan semua rating alternatif yang ada [1].

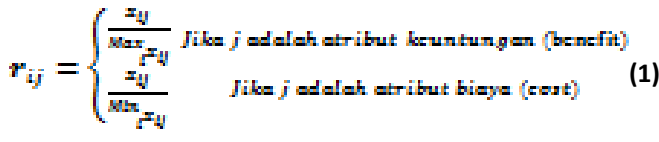

Dimana $\mathrm{r}_{\mathrm{jj}}$ adalah rating kinerja ternormalisasi dari alternatif $A_{i}$ pada atribut $C_{j}$; $\mathrm{i}=1,2, \ldots, \mathrm{m}$ dan $\mathrm{j}=1,2, \ldots, \mathrm{n}$. Nilai preferensi untuk setiap alternatif $\left(\mathrm{V}_{\mathrm{i}}\right)$ dibarikan sebagai:

$$
V_{i}=\sum_{j=1}^{n} w_{j} r_{i j}(2)
$$

Nilai $V_{i}$ yang lebih besar mengindikasikan bahwa alternatif $\mathrm{A}_{\mathrm{i}}$ lebih terpilih.

\section{UML (Unified Modeling Language)}

Alat bantu yang digunakan dalam perancangan dan analisa sistem adalah UML. UML (Unified Modeling Language) adalah suatu bahasa yang digunakan untuk menggambarkan, membangun, dan mendokumentasi suatu sistem perangkat lunak [2].

Empat macam diagram yang paling sering digunakan dalam pembangunan aplikasi berorientasi objek, yaitu use case diagram, sequence diagram, class diagram, dan activity diagram.

\section{Flowchart}

Flowchart adalah bentuk penyajian grafis yang menggambarkan solusi langkah demi langkah terhadap suatu permasalahan [3].

\section{Arduino}

Arduino adalah nama keluarga papan mikrokontroler yang bersifat "open source". Pemrograman arduino dilakukan melalui komputer dan untuk membuat program arduino menggunakan software yang dinamakan Arduino Integrated Development Environment (Arduino IDE) [4].

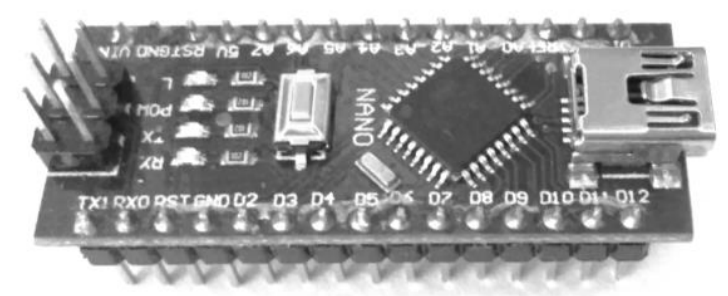

Gambar 1. Arduino

Blynk

Blynk merupakan platform yang menggunakan aplikasi $i O S$ dan Android untuk mengontrol Arduino, Raspberry $P i$, dan lainya menggunakan internet. Blynk merupakan digital dashboard dimana kamu dapat membuat antarmuka untuk setiap project dengan mudah. Blynk tidak terikat pada board tertentu, blynk dapat digunakan pada banyak perangkat keras.

Blynk dibuat untuk Internet Of Things, Blynk dapat mengontrol perangkat keras secara remote, dapat menampikan data sensor, dapat menyimpan data, dan memvisualisasikan data tersebut [5].

\section{DHT22}

Sensor DHT 22 adalah sensor suhu dan kelembapan udara. Rentang kelembapan yang dapat di ukur antara 0\% - 100\% RH dengan tingkat akurasi $\pm 2 \% \mathrm{RH}$ dan sensitivitas $0,1 \% \mathrm{RH}$. DHT 22 memiliki 3 buah pin, yang terdiri dari pin VCC, DATA, dan GND.

Pin VCC dihubungkan dengan tegangan $5 \mathrm{~V}$, pin GND ke ground dan pin DATA ke pin Analog pada mikrokontroler [6].

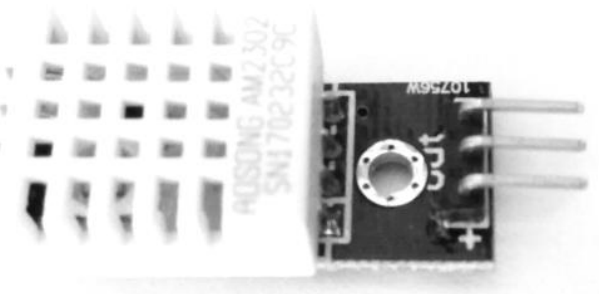

Gambar 2. Sensor DHT22

\section{Soil Moisture}

Sensor kelembapan tanah berguna untuk mengukur kelembapan tanah. Sensor seperti ini dapat dipakai untuk kepentingan penyiraman media tanaman secara otomatis jika kelembapan tanah mencapai ambang tertentu. Sensor kelembapan tanah yang berbentuk modul memiliki dua output yaitu output digital dan output analog, ini digunakan sebagai pembanding pembacaan sensor tergantung dari penggunanya [7]. 


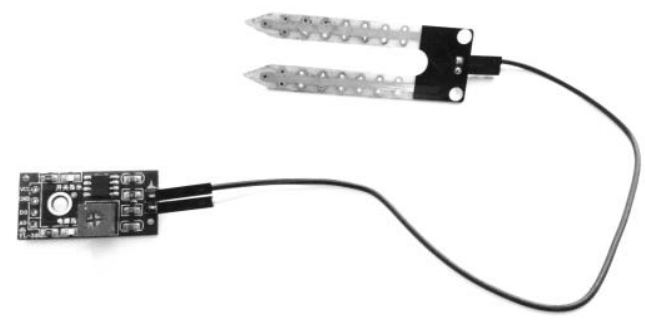

Gambar 3. Sensor Soil Moisture.

\section{Relay}

Relay adalah komponen listrik yang bekerja berdasarkan prinsip induksi medan elektromagnetik. Jika sebuah penghantar dialiri oleh arus listrik, maka di sekitar penghantar tersebut timbul medan magnet. Medan magnet yang dihasilkan oleh arus listrik tersebut selanjutnya diinduksikan ke logam feromagnetik[8].

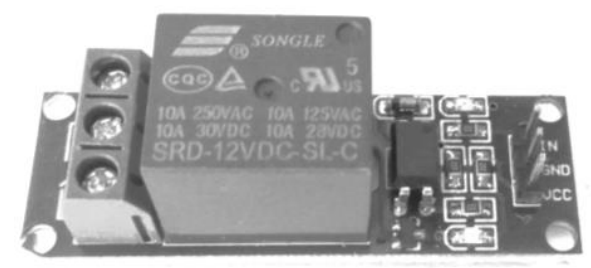

Gambar 4. Relay.

\section{METODE PENELITIAN}

Metodologi penelitian merupakan suatu cara atau prosedur yang digunakan dalam pengumpulan, pengolahan dan penganalisaan data dengan cara-cara ilmiah.

1. Pengumpulan Data

Data adalah sumber atau bahan mentah yang sangat berharga bagi suatu proses yang menghasilkan informasi. Oleh karena itu, pengumpulan data perlu dilakukan secara cermat dan hati - hati sehingga data - data yang diperoleh dapat bermanfaat dan berkualitas. Adapun metode pengumpulan data yang penulis gunakan adalah sebagai berikut:

a. Wawancara

Melakukan tanya jawab dengan rumah tangga yang memiliki tanaman, dan penjual tanaman untuk memperoleh gambaran dan penjelasan mengenai alur yang terjadi di lapangan.

b. Observasi

Penulis mengadakan pengamatan langsung mengenai objek yang diteliti agar diperoleh gambaran yang jelas tentang objek dan permasalahan yang diteliti.

c. Dokumentasi
Membaca dan mempelajari data - data dari buku, internet dan literatur lain yang berhubungan dengan tema yang dapat mendukung dalam penulisan penelitian ini.

2. Metode Pengembangan Sistem

Metode yang digunakan untuk pengembangan sistem adalah model prototype. Model prototype digunakan untuk menyambungkan ketidakpahaman pelanggan mengenai hal teknis dan memperjelas spesifikasi kebutuhan yang diiinginkan pelanggan kepada pengembang perangkat lunak.

Dimulai dari mengumpulkan kebutuhan pelanggan terhadap perangkat lunak yang akan dibuat. Lalu dibuatlah program prototype agar pelanggan lebih terbayang dengan apa yang sebenarnya diinginkan [9].

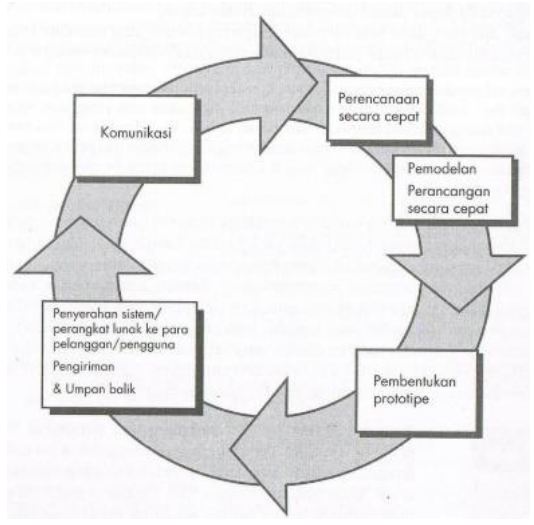

Gambar 5. Model Prototype

a. Komunikasi

Dalam tahap ini pihak pengembang program melakukan wawancara ke pelanggan untuk mengumpulkan kebutuhan terhadap sistem yang akan dibuat. Dalam tahap ini penulis melakukan wawancara kepada pemilik tanaman tentang penyiraman pada tanaman.

b. Perencanaan Secara Tepat

Setelah melakukan komunikasi, dilakukanlah perencanaan tentang apa saja yang dibutuhkan meliputi kebutuhan modul ataupun komponen.

c. Pemodelan Perancangan Secara Tepat

Langkah selanjutnya penulis menggambarkan poin-poin yang akan dibuat dalam sistem seperti perencanaan fungsi alat, tampilan perangkat lunak, dan desain prototipe.

d. Pembentukan Prototipe

Prototipe dibuat berdasarkan pada rancangan antarmuka pengguna, dan rancangan cepat konstruksi prototipe. Dalam pembuatan prototipe akan dimasukkan fungsi - fungsi dasar sistem, desain akan dibuat sesederhana mungkin agar 
pengguna lebih terbayang dengan manfaat sistem yang akan di bangun nantinya.

e. Penyerahan Kepada Pengguna Dan Umpan Balik Prototipe kemudian akan diserahkan kepada para stakeholder dan kemudian mereka akan melakukan evaluasi-evaluasi tertentu terhadap prototipe yang telah dibuat sebelumnya. Dalam hal ini penulis akan mengujikan secara langsung kepada pengguna serta meminta tanggapan tentang alat yang telah dibangun berupa kuesioner yang telah dibagikan.

\section{Sistem}

Sistem didefinisikan sebagai kumpulan prosedur yang saling berkaitan dan saling terhubung untuk melakukan suatu tugas bersama-sama [10].

\section{Monitoring}

Monitoring adalah proses pengumpulan dan analisis informasi berdasarkan indikator yang ditetapkan secara sistematis dan kontinu tentang kegiatan/ program sehingga dapat dilakukan tindakan koreksi untuk penyempurnaan program/ kegiatan itu selanjutnya [11].

\section{PHP}

PHP adalah salah satu bahasa pemrograman skrip yang dirancang untuk membangun aplikasi web. Ketika dipanggil dari web browser, program yang ditulis dengan PHP akan di-parsing di dalam web server oleh interpreter PHP dan diterjemahkan dalam dokumen HTML, yang selanjutnya akan di tampilkan kembali ke web browser [12].

\section{HASIL DAN PEMBAHASAN}

\section{Perangkat keras (Hardware)}

Perangkat keras (hardware) yang di butuhkan dalam membuat alat penyiraman tanaman otomatis adalah sebagai berikut:

\section{Arduino Nano}

Arduino berfungsi untuk menjalankan perintah berdasarkan input data dari sensor yang kemudian dikirim ke blynk cloud menggunakan protokol http menggunakan ethernet shield untuk selajutnya data tersebut menjadi data yang siap di olah.

\section{Analisa Menggunakan Metode SAW}

Metode SAW terdapat kriteria yang dibutuhkan untuk menentukan waktu penyiraman pada sistem penyiraman otomatis berbasis web, adapun kriteria - kriteria yang dibutuhkan adalah sebagai berikut:

a. Idenfikasi Software yang digunakan untuk membuat aplikasi

Software yang digunakan dalam pengembangan aplikasi ini adalah :

1. Microsoft Windows 8
2. Eclipse Juno

3. Android SDK Manager

Tabel 1. Kriteria.

\begin{tabular}{|l|l|}
\hline Kriteria & Keterangan \\
\hline C1 & Kelemban Tanah \\
\hline C2 & Suhu \\
\hline C3 & Humiditas \\
\hline
\end{tabular}

Tabel 2. Bobot

\begin{tabular}{|l|l|}
\hline Keterangan & Nilai \\
\hline Sangat Rendah & 0 \\
\hline Rendah & 0.25 \\
\hline Cukup & 0.5 \\
\hline Tinggi & 0.75 \\
\hline Sangat Tinggi & 1 \\
\hline
\end{tabular}

Nilai tertinggi dari hasil perhitungan menggunakan metode SAW, kemudian nilai tersebut dijadikan acuan sebagai lamanya penyiraman di lakukan yaitu jika nilai akhir lebih dari 0.9 maka akan menyiram selama 10 detik, nilai akhir lebih dari 0.8 akan menyiram selama 5 detik dan jika nilai selain itu maka menyiram selama 3 detik

Tabel 3. Pembobotan Kelembapan Tanah.

\begin{tabular}{|l|l|}
\hline Keterangan & Nilai \\
\hline Sangat Lembap $<200$ & 0 \\
\hline Lembap $>=200$ & 25 \\
\hline Normal $>=300$ & 50 \\
\hline Kering $>=400$ & 75 \\
\hline Sangat Kering $>=500$ & 100 \\
\hline
\end{tabular}

Tabel 4. Pembobotan Suhu.

\begin{tabular}{|l|l|}
\hline Keterangan & Nilai \\
\hline Sangat Dingin $<20^{\circ} \mathrm{C}$ & 0 \\
\hline Dingin $>=20^{\circ} \mathrm{C}$ & 25 \\
\hline Normal $>=25^{\circ} \mathrm{C}$ & 50 \\
\hline Panas $>=35^{\circ} \mathrm{C}$ & 75 \\
\hline Sangat Panas $>=40^{\circ} \mathrm{C}$ & 100 \\
\hline
\end{tabular}

Tabel 5. Pembobotan Humiditas.

\begin{tabular}{|l|l|}
\hline Keterangan & Nilai \\
\hline Sangat Lembap $>=90$ & 0 \\
\hline Lembap $>=75$ & 25 \\
\hline Normal $>=60$ & 50 \\
\hline Kering $>=25$ & 75 \\
\hline Sangat Kering $<25$ & 100 \\
\hline
\end{tabular}

Tabel 6. Pembobotan Kriteria.

\begin{tabular}{|l|l|}
\hline Kriteria & Bobot \\
\hline Kelemban Tanah & $45 \%$ \\
\hline Suhu & $30 \%$ \\
\hline Humiditas & $25 \%$ \\
\hline
\end{tabular}

Perancangan Perangkat Keras 
Perancangan perangkat keras berisi rangkaian / skematis dari alat penyiraman tanaman otomatis yang terdiri dari Arduino Nano, Ethernet Shield, Sensor Suhu dan kelembaban (DHT22), Sensor Kelembaban Tanah dan relay. Berikut merupakan skematis dari alat penyiraman tanaman otomatis :

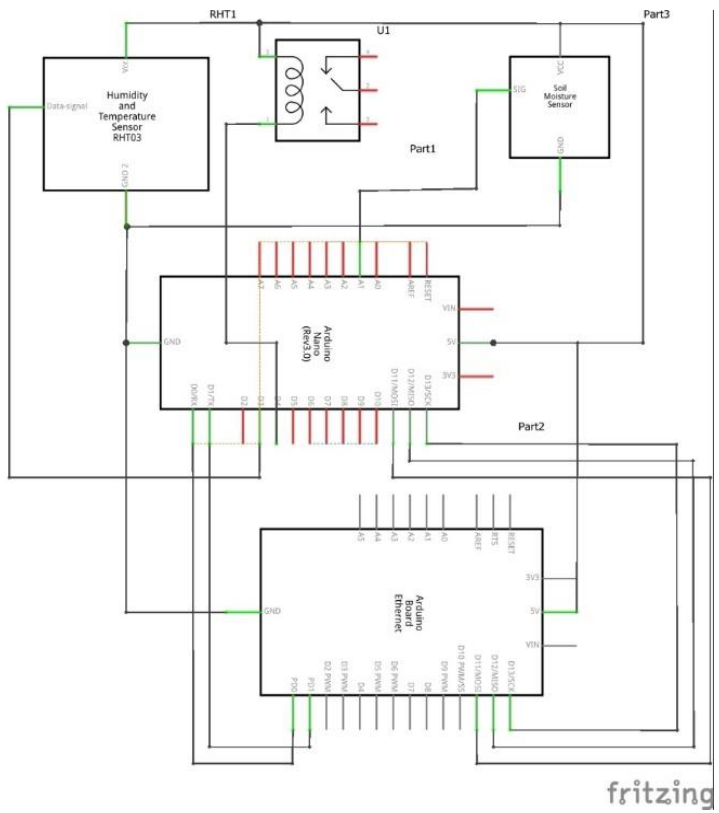

Gambar 6. Rangkaian Skematis Alat Penyiraman Tanaman Otomatis

\section{Implementasi dan Hasil}

\section{Implementasi Alat}

Implementasi alat dari sistem penyiraman tanaman otomatis yang menggunakan arduino nano sebagai mikrokontroler dan sensor suhu dan kelembapan menggunakan adaptor $5 \mathrm{~V}$ sebagai daya utama. Berikut ini hasil implementasi dari perancangan alat tersebut.

a. Bagian Utama Alat

Bagian ini merupakan isi dari keseluruhan sensor dan mikrokontroler pada sistem ini.

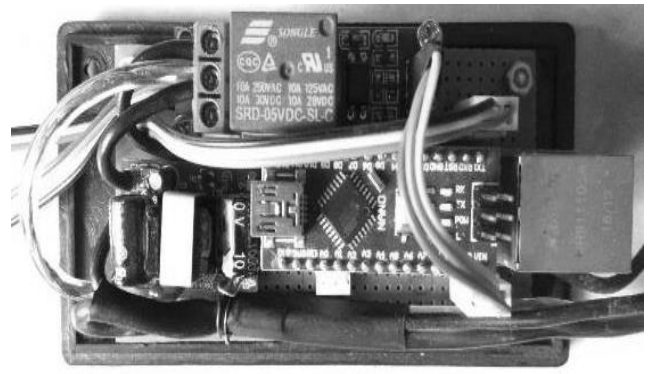

Gambar 7. Bagian Utaman Alat.

b. Semua Bagian Alat

Hasil alat jika telah dirangkai serta di berikan tempat, ditambahkan pula pompa air.

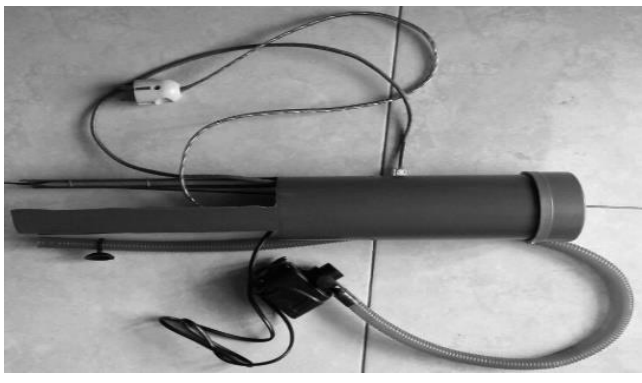

Gambar 8. Semua Bagian Alat.

\section{Tampilan Halaman Program}

a. Halaman Data Pengguna

Halaman ini digunakan untuk menggelola data pengguna sistem penyiraman tanaman otomatis.

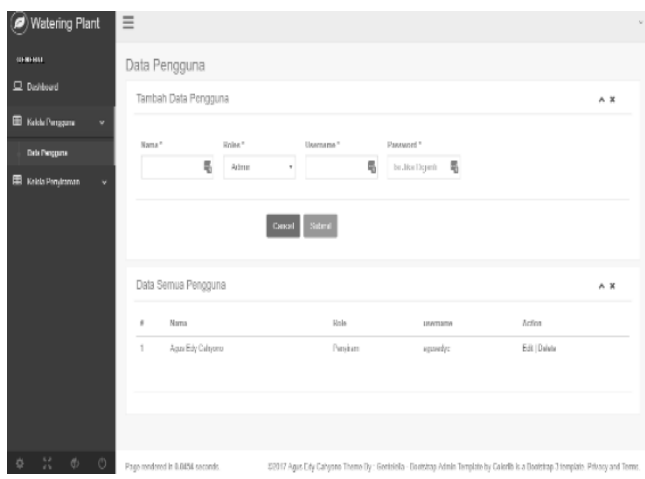

Gambar 9. Halaman Data Pengguna.

b. Halaman Data Alat

Pada halaman ini pengguna sistem dapat melakukan manajeman alat, mendmbahkan alat baru.

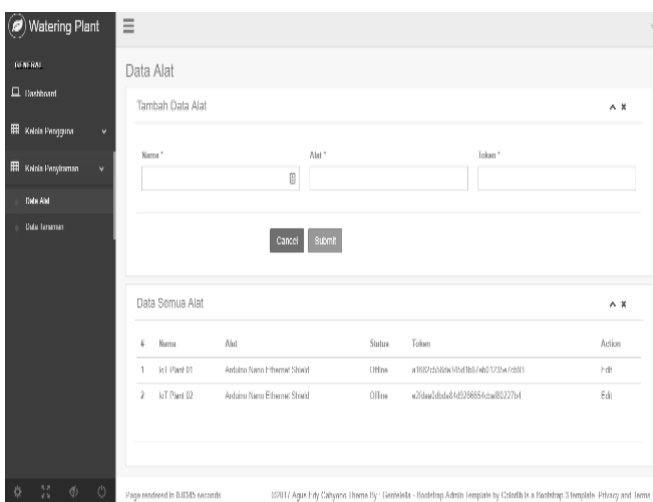

Gambar 10. Halaman Data Alat.

c. Halaman Data Tanaman

Dalam halaman ini pengguna akan dapat melihat data atau status dari setiap tanaman sehingga dapat di monitor tanaman tersebut. 

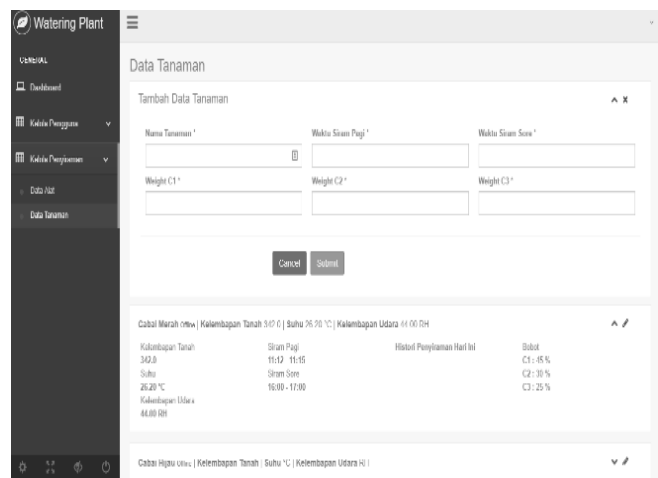

Gambar 11. Halaman Data Tanaman.

\section{KESIMPULAN}

Berdasarkan hasil dan pembahasan sebelumnya maka beberapa kesimpulan yang didapat adalah sebagai berikut:

1. Sistem yang telah dibangun dapat berjalan sesuai harapan, hal tersebut dibuktikan dari pengujian yang dilakukan serta dari responsi pengguna saat menggunakan alat tersebut.

2. Adanya sistem ini penyiraman tanaman dapat dilakukan secara otomatis dan dapat dimonitor untuk mendapatkan data yang sebenarnya dari tanaman tersebut.

3. Data dari pembacaan sensor dapat di olah menggunakan metode SAW yang menghasilkan rangking nilai, nilai tertinggi yang paling sesuai dengan bobot digunakan untuk menentukan lamanya penyiraman tanaman.

4. Penghematan air dapat dimonitor dengan menggunakan alat ini karena air yang dikeluarkan sesuai dengan kondisi tanaman pada saat itu, sesuai dengan hasil perhitungan menggunakan metode SAW, yang menentukan lamanya air yang dikeluarkan sehingga dapat efektif untuk menyiram tanaman.

\section{Saran}

Berdasarkan hasil penelitian yang dilakukan, maka beberapa saran yang dapat penulis berikan adalah sebagai berikut:

1. Untuk meningkatkan kualitas penyiraman perlu dilakukan penelitian lebih lanjut tentang penggunaan metode untuk pengambil keputusan yang lebih baik pada kasus penyiraman tanaman. Sehingga manfaat alat ini untuk dapat menyiram tanaman lebih dapat berfungsi dengan optimal.

2. Untuk mendapatkan hasil dari pembacaan sensor yang optimal dibutuhkan peningkatan kualitas sensor yang lebih baik sehingga dalam pembacaan di dalam tanaman data yang di dapat di olah dengan tepat.

3. Penggunaan mikrokontroler dapat dilakukan perubahan karena penggunaan arduino menurut penulis masih kurang stabil untuk digunakan pada sistem yang bekerja pada lingkungan terbuka dan bekerja selama 24 jam setiap harinya.

\section{DAFTAR PUSTAKA}

[1] Kusumadewi, S.d., (2006), Fuzzy MultiAttribute Decision Macking ( Fuzzy MADM), Yogyakarta: Graha Ilmu.

[2] R.A.S.d.M., (2014), Rekayasa Perangkat Lunak, Bamdung: Informatika.

[3] Kadir, A, (2013), Pengenalan Algoritma Pendekatan Secara Visual dan Interaktif Menggunakan Raptor, Yogyakarta: Andi.

[4] Kadir, A, (2015), From Zero to A Pro Arduino, Yogyakarta: Andi.

[5] "Blynk" http://www.blynk.cc/ (Diakses pada 5 April 2017).

[6] Aosong Electronics, (2017), Digital relative humidity \& temperature sensor.

[7] Kadir, Abdul, (2015), From Zero to A Pro Arduino, Yogyakarta: Andi.

[8] Santoso, H., (2013), Pengertian Fungsi, Prinsip, dan Cara Kerja Relay, (Diakses pada 5 April 2017).

[9] Pressman, R. S., (2012), Rekayasa Perangkat Lunak, Yogyakarta: Andi.

[10] Darmawan, D. \& Permana, H., (2013), Sistem informasi Manajemen, Bandung: PT Remaja Rosadakarya Offset.

[11] Widiastuti, N. I. \& Susanto, R., (2014). Kajian Sistem Monitoring, Majalah Ilmiah UNIKOM.

[12] Raharjo, B. \& dkk, (2014), Rekayasa Perangkat Lunak, Bandung: Informatika. 